\title{
7 Incentives to Change
}

\section{The Experience of the Organic Sector}

\author{
Gábor Figeczky, Louise Luttikholt, Frank Eyhorn, \\ Adrian Müller, Christian Schader and Federica Varini
}

\section{The Need for Change}

If we as society want to see real change in the world and move towards true sustainability, the real cost of our current food system needs to be made evident-and eventually reflected in the price-so that all participants can take full responsibility for their actions. We need to change how we treat the environment and use natural resources, as well as how we interact with each other when it comes to food and agriculture. Organic agriculture, which has been practised for several decades now, can teach many lessons about how to steer such a transformative process effectively.

\section{Organic Agriculture: Farming with Lower External Costs}

Organic agriculture aims at sustaining the health of soils, ecosystems, and people. It relies on ecological processes, biodiversity, and cycles adapted to local conditions, rather than the use of inputs with adverse effects. Organic agriculture combines tradition, innovation, and science to benefit the shared environment and promote fair relationships and good quality of life for all involved. The principles of health, ecology, fairness, and care are the roots from which organic agriculture grows and develops. They express the contribution that organic agriculture can make to the world and a vision to improve all agriculture in a global context. In practice, this translates into reliance on natural ecosystems by mimicking nature and enhancing soil quality, greater biodiversity, and radically reduced impacts from synthetic inputs, such as chemical pesticides, fertilizers, and antibiotics, and the aspiration to improve livelihoods through more fairness and resilience. Organic agriculture has a long history of success and a growing market share now worth $\$ 120$ billion globally for certified organic alone. In addition, millions of small-holder farmers, particularly in the Global South, also practice these methods, still adhering to the traditional practices of their ancestors. Recognizing the wide range of systems based on the principles of organic agriculture, the organic movements have agreed to embrace organic agriculture in its full diversity (IFOAM-Organics International, 2017). 
Building on this, organic agriculture allows for farming with lower external costs and the ability to deliver more positive externalities (van der Werf et al., 2020; Seufert and Ramankutty, 2017) than the prevailing agricultural system.

The potentially lower yield performance of organic versus conventional systems is usually put at the center of the discussion when comparing sustainability per unit of product (Meemken and Qaim, 2018, Seufert, 2018). Current estimates of the yield gap are about $20 \%$, but there are indications that this can be considerably reduced if due focus is laid on diversity in crops and crop rotations, etc. (Ponisio et al., 2015). When comparing the environmental performance of conventional and organic systems on the whole and in relation to the natural environments where they are located, it is clear that high productivity in intensive agriculture is to the detriment of the health of ecosystems and our planet, as it contributes to countless externalities, the costs of which are paid by society. A truly sustainable agriculture and food system is not performing maximally on one indicator (e.g. yields) and badly on all others (e.g. pesticide contamination, nutrient surplus), but is set up to perform relatively well on all sustainability indicators, thus also optimally managing potential trade-offs (e.g. between high yields and transgressing local ecosystem carrying capacities). Thus, the debate on comparing agricultural production systems needs to go beyond mere yield or greenhouse gas footprint comparisons and has to build on encompassing systems comparisons based on total impacts (as shown, e.g., in Müller et al., 2017; van der Werf et al., 2020). TCA can provide a helpful conceptual framework to support such approaches in practice.

\section{True Cost Accounting, an Approach to Transform Food Systems}

Modern economies are designed in a way that consumers actually pay, in the end, three or even four times the cost of seemingly cheap food. They pay a lower retail price for the product, and then without realizing it consumers also finance, through tax payments, the mitigation of the negative impacts of production (e.g. to clean up drinking water). Some actors in mainstream food systems are allowed to pollute without having to pay for it and become disproportionately wealthy and powerful. They become politically influential and put pressure on governments to use money from taxpayers to further subsidize unsustainable agriculture through government schemes promoting the purchase of synthetic fertilizers or intensive animal husbandry. In the end, citizens bear the health costs of noncommunicable diseases caused by unhealthy food or environmental pollution. TCA can help governments and consumers understand and identify these "hidden costs," making them visible and quantifiable while at the same time revealing the societal benefits of more sustainable systems such as organic farming (IFOAM-Organics International, 2019).

TCA provides strong arguments for policy reforms that incentivize beneficial practices and systems and disincentivizes harmful ones (Eyhorn et al., 2019) (Figure 7.1). 
Current System

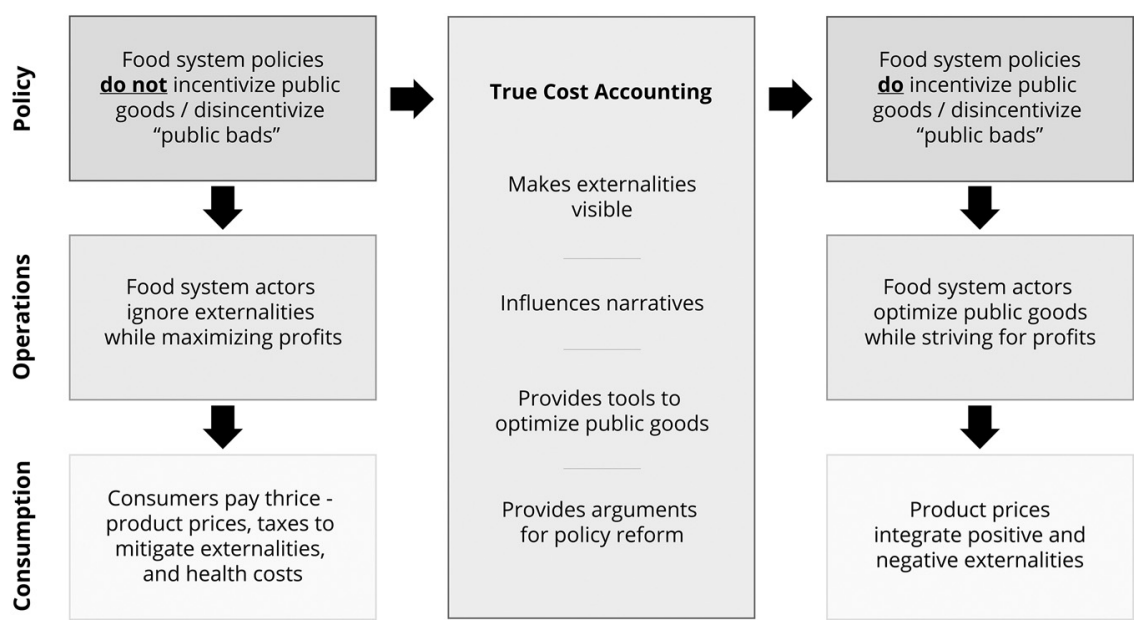

Figure 7.1 The theory of change of TCA.

Some people consider it unethical to value aspects of our world in monetary terms, for example, the beauty of a landscape, the survival of an endangered species or, ultimately, human life. In the organic sector we recognize that the currency of nature is life itself and that many phenomena cannot be expressed through money alone.

Money, however, is universally understood as a way to assign value in societies across the world and as a means to inform decisions on the use of scarce resources. Therefore, notwithstanding its limitations in accurately reflecting societal costs and benefits, TCA is an important tool for change and offers a way to correct some core failures in our current model, where profits are privatized while the rest of the costs are borne by society. TCA makes these external costs, public good provision, and ecosystem services visible to the decision-makers. If used as a basis for regulations or policies, it thus forces operators to account for the externalities that their operations might cause, as they directly influence their private profits.

\section{What to Measure, How to Measure: The Challenges Behind Accounting for Externalities in the Food System}

Environmental as well as human costs and benefits add up as products move through the value chain, to the end consumer. For instance, the overall impact of processed food depends on the environmental impacts of the production of its raw ingredients, the transformation processes that these ingredients undergo, as well as the distribution of the final product, including packaging, transportation, storage, etc. and, if relevant, also the impacts of its remains that might become waste. 
The true- or full—cost of any given product, activity, enterprise, sector, production model, or system will inevitably be only an approximation, or an incomplete snapshot, limited by a given set of boundaries over a given period of time. The calculations will always show some uncertainty, and results might vary but, importantly, they consistently help to identify whether key practices and their impacts move in a positive or a negative direction; and they can facilitate identification of particular trade-offs and synergies between different aspects along the value chain and between different sustainability indicators.

An extensive amount of scientific literature has explored possible models for evaluating the costs linked to pollution, the environmental impact of certain value chains, as well as for calculating the economic value of the environmental services provided by agriculture. Life Cycle Assessment (LCA) studies focus on the environmental impact of single products measured by impacts per unit of product, disregarding total impacts of a whole production system. Owing to this narrow view, products from intensive production systems tend to perform better in such comparisons. Looking at these systems with a broader perspective, however, accounting for their total impacts in relation to relevant local and regional ecosystem boundaries or also planetary boundaries, we find that their environmental sustainability is lower (Geiger et al., 2010; Gibbs et al., 2009; Meehan et al., 2011). Furthermore, agricultural production is multifunctional, and all outputs besides the core product, such as ecosystem services provision, need to be accounted for when doing an encompassing assessment. LCAs that compare whole farming systems thus need to look at all the outputs produced by agriculture and allocate the environmental impacts to these (Schader et. al., 2012). Thus, previous efforts to account for externalities, such as LCA, have a number of shortcomings that TCA should seek to address.

None of this is simple. In order to reverse the unsustainable course of agriculture, we need to start with the key leverage points, such as nitrogen inputs and pesticide use, and continue to add criteria and refine the methodology continuously over time. A focus on specific practices can serve as a powerful initiator of change that will compel other changes in a similar direction, eventually leading to sustainable agriculture and food systems.

\section{Incentives to Change: How Policies Apply TCA to Transform Food Systems}

\section{Accounting for True Costs Through Policies: Creating a Level Playing Field for All Food Production Systems}

An examination of how TCA has been implemented in lawmaking, in order to create a more conducive policy environment for organic agriculture, makes it possible to distinguish two main types of measures adopted: incentives 
(subsidies on agri-environmental measures) and disincentives (taxes). These instruments, given primarily as market support, are justified politically through consistent evidence showing the multiple societal benefits delivered by organic farming in contrast to the detrimental environmental impacts of industrial agriculture. However, governmental support for the organic sector remains too often a marginal intervention for a niche market, while unsustainable practices, such as the use of chemical inputs in the name of achieving food security, or intensive animal husbandry, remain heavily subsidized. The overall agricultural policy package is therefore incoherent. In the next section we provide some concrete examples of policy measures from different contexts.

\section{Incentives Through Agri-Environmental Measures}

Income support for organic producers is generally included under policy interventions dedicated to support agri-environmental measures. As previously argued, the political reasoning for subsidizing organic agriculture resides in the multiple socioeconomic and environmental benefits that this type of production delivers. These positive externalities are partly remunerated by the market itself in the form of a premium price, as well as through specific subsidy programs. These subsidies are usually given to organic farmers or farmers in conversion to organic in the form of a fixed amount per hectare or as a reward for voluntary agri-environmental measures implemented. Such forms of support are meant to foster a wider adoption of organic agriculture among farmers. Subsidies given during the conversion period are often higher than those received for maintaining a business under organic production. This is due to the fact that during the conversion period, the farmer bears the additional costs of organic production without yet receiving the benefit of the premium prices for their products.

In Europe and the USA, but also in certain Latin American and Asian countries, the organic sector has benefited in the last two decades from different forms of subsidy redistribution.

In Asia, South Korea is one of the first states to have implemented direct payments to organic producers to support their income. Starting in 1999, in agreement with the Environment-Friendly Agriculture Promotion Act, farmers certified as performing environmentally friendly agriculture are rewarded with direct payments which differ according to the certification category (organic production gets higher payments compared to no-pesticides or low pesticides), type of crop, and the area cultivated. The total budget earmarked to this type of payments was approximately €188.5 million between 1999 and 2012, €23 million in 2013, €19 million in 2014, and €23 million in 2015 (Choi, 2015).

Since 2015 India has had a program which includes direct payments dedicated to small-scale producers performing organic farming. The Paramparagat Krishi Vikas Yojana (PKVY) program, running under the National Mission on Sustainable Agriculture, supports small producers that organize themselves in clusters under organic production. The subsidy covers a variety of costs, such as 
input purchase, harvesting, transportation of costs, marketing and also a direct payment based on area. The total amount allocated for the scheme in the period 2015-18 was $€ 118$ million, and the government estimates that under this scheme 237,820 hectares of land were converted into organic farming land, and 394,550 farmers benefited from the support. Although the Indian government provides support to organic farming through different programs, the reality is that the majority of government support is allocated to conventionally grown cash crops under monocropping conditions. This is especially true if one looks at the support for agricultural inputs: in 2017-18 the Indian government allocated approximately $€ 9$ billion to provide subsidies for synthetic fertilizers. In comparison, the two dedicated programs for organic farming-PKVY and MOVCDENR ${ }^{1}$-were supported over the period 2015-18 with approximately $€ 168$ million. In 2018 India had almost 2 million hectares under organic production, which is equal to about $1 \%$ organic share of its agricultural land (Willer et al., 2020).

In Central America, Costa Rica represents an example of a country that has also implemented area payments for conversion. Since 2007 this measure supports small and medium-sized organic farmers allocating the subsidy according to the type of crop over a period of three years. Interestingly, such a measure is funded by a taxation scheme imposed on fuel. In 2018, for instance, the government disbursed a budget of $€ 424,000$ for the implementation of this measure.

In Switzerland, direct payments are a central element of national agricultural policy, and farmers are eligible to apply for direct payment only if they comply with certain environmental requirements. These cross-compliance criteria include a set aside area of at least $7 \%$ of the utilized agricultural area, reduction of soil erosion and nutrient run-off, and basic requirements for good agricultural practices. Until 2014 a distinction was made between general direct payments and environmentally friendly payments. However, as the Swiss agricultural policy known as AP14-17 has now been extended until 2021, this distinction is not in place anymore, and seven types of contributions have been introduced: maintenance of the cultural landscape, ensuring food supply (which include support for farming systems in unfavorable areas), biodiversity, landscape quality, production systems (which includes support to organic agriculture), and efficient use of resources and transition contributions (to ensure a socially sustainable transition from the old to the new policy). Farmers are eligible to receive these types of payments only if they comply with some stringent environmental performance requirements (PER) that cover domains such as animal welfare, biodiversity, nitrogen surpluses, soil management, and phytosanitary products. As a result of this reform, the funds are used more specifically in favor of production systems delivering services of public interest which are not automatically remunerated by the market (i.e. improvement of animal welfare and promotion of biodiversity). In 2018 organic farming reached 156,098 hectares (15\% of the total agricultural land), an increase of more than 10,000 hectares $(+7 \%)$ compared with the previous year. In total, more than $€ 51$ million was paid out in 2018 for the promotion of organic farming - that is, €4.6 
million more than in 2017, which equals approximately $2 \%$ of the total expenditure on direct payments in the country. However, payments are cumulative and organic farms are eligible for further Ecological Direct Payments (Swiss Federal Office for Agriculture, 2004).

In the USA, there are a number of programs at the United States Department of Agriculture that support the organic sector. For example, the voluntary Environmental Quality Incentives Program (EQIP), introduced in 1985, provides technical and financial support to farmers engaging in conservation practices. Organic farmers have a dedicated sub-program within EQIP aiming at accompanying farmers in the conversion phase. This successful program ran with a budget of $\$ 1$ billion reaching more than 6,800 farms in 2016 . Additional programs have since been designed and implemented, some on a state rather than federal basis (see Chapter 9, "Fostering Healthy Soils in California: Farmer Motivations and Barriers"). Other programs are not as well funded, unfortunately, such as the Organic Transitions Program (which provides support for producers wishing to transition to organic farming, funded recently at only $\$ 4$ million) and the Organic Agriculture and Research Extension Initiative (funded recently at only $\$ 20$ million).

Almost all member states of the European Union (EU) offer a dedicated measure for area conversion and/or maintenance payments for organic producers included among other agri-environmental measures under Pillar 2 of the Common Agricultural Policy (CAP). The CAP, which represents almost 40\% percent of the total EU budget, is indeed the most powerful policy instrument shaping EU food systems since 1962. The CAP cycle 2014-2020 made organic farming more prominent, corroborating its value as production practice able to deliver on sustainability targets in the agri-food sector under its two main components of the policy, Pillar 1 and 2. Approximately half of the budget is earmarked to Pillar 1, which provides support to income for farmers in the form of direct payments. Since 2015 Member States must use at least $30 \%$ of their national direct-payment allocations to fund the greening components introduced to provide additional support to offset the cost of delivering environmental public goods not remunerated by the market; organic farms automatically receive such additional support without having to fulfill any additional requirements.

Public support dedicated through the CAP in recent decades has contributed to the development of the organic sector at a communitarian level, with the share of organic farming area in total utilized agricultural area (UAA) in 2018 reaching almost 8\% (Willer et al., 2020). None the less, despite being the most significant type of financial support to organic agriculture in Europe, the CAP 2014-2020 earmarked to the organic sector a mere 1.5\% (€6.3 billion) of current EU agricultural spending (Stolze et al., 2016). In a dedicated report, the European Court of Auditors (2017) highlighted how the current CAP still presents important shortcomings when addressing environmental degradation and climate change challenges, as well as economic sustainability issues related to the agri-food sector. The main shortcoming is that so far most 
of those payments are provided as income support for fulfilling the policy's minimum conditions and are based on the amount of land that a farmer owns without being conditionally linked to result-orientated and quantifiable targets. In the attempt to overcome and improve the sustainability performance of the policy, the European Commission is working on a new CAP proposal for 2021-2027, with a view to implementing it starting from 2022. The most relevant innovation is introducing more margin for local adaptation at Member State level while at the same time making it compulsory for each country to adopt the Green Architecture, which introduces the possibility for producers to voluntarily apply for environmental measures, included not only for the Rural Development (Pillar 2) but also for direct payments (Pillar 1).

Besides these instruments based on compensating farmers for the income forgone owing to the implementation of organic practices, several other policy measures have been implemented worldwide to sustain the development of the organic sector. This is done by fostering production, consumption, or by creating an enabling environment for the development of the sector. In 2017 IFOAM-Organics International published extensive research which looked at public support provided to organic agriculture in over 80 countries, spanning from support to inputs development to free organic certification or promotion of public food procurement prioritizing organic produce (IFOAMOrganics International, 2017).

\section{Moving Towards Environmental Payments Tied to Result-Orientated Objectives}

Although the basic policy justification behind these subsidies is to reward environmental and societal benefits, the calculation methods used by governments to determine the level of payments for various types of production or environmental measures adopted have so far not been based on defining a value for those positive externalities, but rather on compensating the additional costs and income foregone from farming organically or adopting agri-environmental measures.

For this reason, such policy incentives still remain a somewhat imperfect tool to apply TCA into policymaking, as payments remain mainly constrained by the "extra cost or loss of income" as dictated by the World Trade Organization $(\mathrm{WTO})^{2}$, which was introduced to respect the principle that agri-environmental payments should not create trade distortions (Burton and Schwarz, 2013). This requirement has been, for instance, strictly observed by the European Commission and its Member States when designing its agri-environmental scheme, preventing the adoption of innovative environmental mechanisms better equipped to link environmental performance to the level of payment.

Allocating payments according to the degree of achievement against predetermined sustainability targets requires complex models and analytical frameworks, which have not yet been fully integrated into lawmaking. So far, only the Tuscany Region in its Rural Development Programme for the period 
of 2014-20 includes a unique attempt to bring in a holistic evaluation when comparing organic farms with conventional systems (see Box 7.1).

The ultimate goal should be to encourage farmers to adopt a selected variety of agri-environmental measures tailored to the pedo-climatic area where they are operating. Thus, policymakers could focus their interventions and support on local needs like decreasing soil erosion or nitrogen leaching.

\section{Box 7.1 Defining Area Payment for Organic Farming in the Tuscany Region, Italy}

EC Regulation 2078/92 institutionalized the promotion of organic farming in the European Union (EU) as a result of the explicit beneficial impact at an environmental and landscape level. The current calculation of the payments level for any agro-environmental scheme in the EU, however, is defined by the EAFRD ${ }^{3}$ regulation (1305/2013) (European Union, 2013) as a compensation for all or part of the additional costs and income foregone resulting from the commitments made by the beneficiary. Likewise, the payments related to Measure 11, which grants support for maintenance or conversion to organic farming as part of the second pillar of the current Common Agricultural Policy, also follow this rule. The additional costs and forgone income are defined by Member States based on parameters such as differences in yield, production costs, prices, and transaction costs. Therefore, this system, despite being motivated by the acknowledgment that "market failure" should be compensated, does not recognize or address the cost or benefits related to the environmental or social dimension linked to the performance of organic farming systems.

In the model used by the Tuscany Region to define the level of payment under Measure 11, the foregone income and the value of the ecosystem services provided are calculated using a set of modelling frameworks developed in collaboration with the University of Florence (Pacini et al., 2015). This model includes a great variety of ecological (i.e., biodiversity, nitrogen leaching, soil erosion, pesticides risks, etc.) and financial indicators (i.e., gross margin, expenses, depreciation, etc.) that allows comparison of the economic and environmental performance of organic and conventional systems. The model adopted by the Tuscany Region is limited to area payments only for arable crops such as cereals, leguminous, and oleaginous crops and mixed farms with livestock and arable crops.

Even though this model applies to a limited type of farms, the Tuscany Region's Rural Development Programme calculates the direct payment for Measure 11 as an estimation of the ecosystem services delivered by organic farms in a specific pedo-climatic area, through the economic and environmental evaluation of a complex model.

As a result, the framework defines a level of payment that presents an increased efficacy compared to the classic calculation based only on the cost-benefit balance. 
The problem of improved efficiency and effectiveness of agri-environment payments is indeed a complex one, as finding methods to increase effectiveness and efficiency in real life conditions is challenging. So far, we are lacking models and scientific methodology able to validate on a farm and field scale the benefits while simultaneously including farmer perspective and behavior, production, and pedo-climatic conditions and a range of environmental potential impacts such as biodiversity decrease, pesticide risk, nitrogen pollution, soil erosion, and conservation of ecological infrastructures. The model in the Tuscany Rural Development Plan is meant to address precisely this gap at least for a limited typology of farms.

However, according to Pacini et al. (2015):

...further optimization of the cost-effectiveness of intended policy measures could result from an identification of the efficiency of resource use/production of ecosystems services of a given farm type as compared to the efficiency of an ideal farm.

If this would be achieved, the payments dedicated to organic farming could be fine-tuned to their efficiency performance, ensuring a continuous improvement of farming practices and stronger environmental achievements.

\section{Disincentives Through Taxation}

Rewarding positive externalities while minimizing the impact of the negative ones should always be the dual objective of consistent and conducive policymaking supporting an agroecological transition. This should be translated into a coherent policy approach that provides support for producers implementing best practices and also increases legal requirements (i.e., in the area of ecosystem conservation or environmental protection) and levies environmental taxes to disincentivize unsustainable practices.

In the agricultural sector, there are some examples of how economic instruments try to place the economic consequence of pollution and health harm on those responsible for it, thus internalizing the negative externalities. Environmental taxes, or taxes and levies on pollution, are one of these examples and they can be implemented to, for example, discourage nitrate run-off and leaching from farming activities or to reduce greenhouse gas emissions. Taxes and levies can be also applied on inputs such as chemical fertilizers and pesticides.

Several studies (Böcker and Finger, 2016; IFOAM EU, 2018; Slunge and Alpizar, 2019) highlight the effectiveness of taxes on pesticides, if coupled with an additional set of supporting measures that can be included in National Action Plans for an agroecological transition. These should be implemented as highly differentiated tax schemes, which are calculated based on the damage caused by a 
certain input on the environment. These taxes can be even more effective and create more incentives if they remove taxation or offer lower tax rates for those products that are less hazardous (i.e., plant protection products accepted in the production standards for organic agriculture, as is done in France and Italy with a lower value-added tax [VAT]). The target of these taxes can be two-fold: on the one hand, taxes on chemical pesticides might aim at producing revenue, while on the other hand, they can target a decrease in adoption of harmful substances.

In Europe several countries, including Norway, France, and Denmark, have been adopting taxation schemes on pesticides with different degrees of success.

In 1988 Norway introduced its first tax on pesticides. The country has now a differentiated tax, based on seven categories with a focus on the risks for human health and the environment. All pesticides for professional use are tested according to several criteria and then categorized in a low, medium, or high risk. Products allowed in organic farming are exempted from the tax. An impact assessment of the scheme revealed a decrease in the number of detected residues in the water.

Denmark introduced its first tax on pesticides in 1982, which back then was only for impacting consumption from households. After several reforms that extended the taxation schemes to agricultural products as well, the current taxation program, enforced since 2013, is considered to have played a major role in reaching the governmental goal of reducing the use of pesticides by $40 \%$ in the period 2013-15 (See Box 7.2 for the case study).

In India, from 2005 onwards, the Sikkim state government gradually phased out subsidies on chemical fertilizers and pesticides. This made inputs costlier in order to embrace other strategies to ensure sustainable soils and plant protection. This measure was coupled with a gradual closing-down of the selling points of synthetic inputs and a levy restricting their import. As a final step, the Sikkim Agricultural, Horticultural Inputs and Livestock Feed Regulation Act, $2014^{4}$ ratified the ban on the import of synthetic agricultural inputs and selling any of such substances in the state. These measures were combined with programs to support farmers in producing their own plant protection products and fertilizers on the farm.

In 2014 the government of Mexico, in an attempt to address the high amount of pollutants and contamination derived from inputs used in agriculture, imposed an excise tax on pesticides according to the level of their toxicity. The government collected more than $€ 83$ million through this scheme between 2012 and 2017. There are plans to earmark these funds to increase efforts of alternative pesticide control and promote more agroecological practices.

\section{Box 7.2 Pesticides Taxation in Denmark}

Pedersen and Nielsen (2017) undertook a comprehensive assessment of the performance of pesticides policies in Denmark in the period 1986-2015. According to their analysis, Denmark, which has been implementing different pesticide taxation schemes since 1982, can be regarded as the European pioneer in terms of policy intervention tackling the reduction of pesticides 
use. It is also important to highlight that these policy interventions were promoted and enforced by a large spectrum of political parties owing to the strong Danish tradition of ensuring protection to their precious groundwater reservoirs, which are used as a source of untreated drinking water and therefore need to be protected from agricultural runoff (Pedersen and Nielsen, 2017).

The previous tax scheme, which enforced an ad valorem tax on retail prices of pesticides between 1996 and 2012, proved to be inefficient to reach the targeted reduction of pesticide use to $50 \%$, as it did not have a built-in incentive for farmers to choose the least hazardous pesticides. In 2013 a new scheme reformed the taxation policy on pesticides introducing a better proxy to evaluate the effect of the scheme (Pedersen and Nielsen, 2017). This new indicator, the Pesticide Load $(\mathrm{PL})$, gives information about three dimensions of the use of a certain pesticide, comprising sub-indicators for the risk on human health as a result of exposure of the operator, the ecotoxicology on non-target organisms, and the persistence and accumulation in the environment. In this new scheme, the tax on pesticides became a differentiated pesticides tax, as the tax fee is calculated for every single pesticide through an individual assessment that takes into account the different aspects mentioned above. According to this tax design, higher taxation rates apply to more harmful pesticides, and in general the tax rates were more than doubled compared with the previous scheme, making Denmark one of the countries with the highest taxation rate for pesticides worldwide. The objective of the new taxation scheme was to reduce the PL by $40 \%$ by the end of 2015 compared with that estimated in 2011 (Ministry of Environment and Food, 2017; Pedersen et al., 2020).

The tax revenues are mainly redistributed to the agricultural sector, reimbursing farmers through a reduction of taxes on land. This constitutes an incentive for reducing the use of pesticides, as producers would then have the benefit of low pesticide tax and lower land tax (Pedersen and Nielsen, 2017). In 2017 the tax revenue amounted to approximately $€ 71$ million (Pedersen et al., 2020).

A recent assessment done by the Danish Environmental Protection Agency shows that this new taxation scheme achieved indeed a substantial reduction in PL from before the tax introduction until the season 2016/17 within the range of $12-27 \%$ (depending on baseline year) according to farmers' registered pesticide use (Pedersen et al., 2020), going up to $44 \%$ if we considered sales figures for the period 2011-17 (Pedersen et al., 2020). The difference between use and sales figures are due mainly to hoarding behavior that happened before the introduction of the new tax and which might still cause a reduction in sales today (Pedersen et al., 2020). Despite the substantial reduction, the objective of reaching $40-50 \%$ load decrease, as was estimated in ex ante analyses prior to the tax introduction, has not been achieved yet (Pedersen et al., 2020). 
The demand of pesticides among European farmers has proved to be rather inelastic (Pedersen et al., 2020). Over the years the different policies on pesticides have struggled to reach their objectives as a consequence of incorrect ex ante policy analysis. The expected result of the policy did not take into consideration that some farmers might respond to such taxes in a way that economically does not make sense. These farmers, instead of focusing on the production costs, aim primarily at increasing yields over all other dimensions and are less concerned about pesticide prices.

In synergies with its taxation schemes on pesticides, Denmark has been implementing since 1986 different National Pesticides Action plans aiming at reducing the quantity of approved pesticides used in the country, as requested also by the Directive 2009/128/EC, article 4 (European Commission, 2016). Beside the taxation scheme, these plans have introduced over the years different sets of measures, such as support to research, stricter approval procedure for pesticides, mandatory spraying certificates for professional users of pesticides, creation of buffer zones around watercourses and lakes, an increase in the share of organic farmed land, and advice to farmers on reduction of pesticide use (Pedersen and Nielsen, 2017).

Less effective and more difficult to implement is indirect taxation on specific food products, for instance by differentiating VAT on products issued by organic farming and those issued by industrial agriculture enterprises. Applying different VAT rates that favor organic products over non-organic ones is likely to be perceived as against the principle of neutrality, which ensures that similar products should be taxed in the same way to ensure fair competition. In reality, even though certification provides a tool to distinguish between organic and non-organic products, it is still arguable that the properties of the final product (i.e., organoleptic ones) are actually dissimilar.

It is, however, important to mention that, as the economic impact of environmental taxes, such as those on chemical pesticides owing to the low-price elasticity of pesticides, are likely to be paid for by end-consumers, with higher impacts on the lower-income consumers, governments should couple this type of intervention with re-distribution of tax revenue or reduced taxes on, for example, labor.

\section{The Rugged Road Ahead}

TCA can help to achieve a better understanding of the sustainability benefits and threats coming from different agricultural actions, practices, and systems and contribute to better decisions. In order to truly benefit from this potential, a number of changes are needed. 
We suggest first to focus on approaches that are robust - that is, their beneficial consequences do not depend much on the exact cost estimates used, address the most pressing problems, and do not result in trade-offs and inconsistencies. TCA can be used, for example, to establish a tax on key pollutants from agriculture, namely nitrogen, pesticides, and greenhouse gases, as well as to support practices that promote soil fertility and biodiversity.

Nitrogen is problematic when applied in levels beyond the amount that can be continuously recycled in a circular system. Thus, taxes on nitrogen sources external to some regional ecosystem boundaries are a measure that could be established, complemented with support payments for practices that build on reduced nitrogen inputs, such as grass-based feed harvested largely on-farm, etc.

Second, taxes on carbon dioxide $\left(\mathrm{CO}_{2}\right)$ emissions from fossil fuels could be established. If a nitrogen tax is implemented, it is less necessary to establish a general carbon tax in agriculture that also works on nitrous oxide $\left(\mathrm{N}_{2} \mathrm{O}\right)$ and methane $\left(\mathrm{CH}_{4}\right) . \mathrm{N}_{2} \mathrm{O}$ is covered by the nitrogen tax, as less nitrogen fertilizer input in farming results in lower nitrous oxide emissions from soils. Taxing $\mathrm{CH}_{4}$ would put ruminants at a disadvantage, although they play a central role in sustainable food systems by converting feed from non-arable grassland areas into food, which is not possible otherwise. To work on $\mathrm{CH}_{4}$ emissions, support for $\mathrm{CH}_{4}$-mitigating measures in herd management (e.g., increasing the number of lactations) and manure application as well as housing could be provided. For pesticides, the tax level could be linked to some gross estimate of their damage potential. Some impacts, however, could be deemed unacceptable, so that bans need to be established and enforced.

Regarding soil fertility and biodiversity, support payments could work best. For soil fertility, it can be linked to soil-organic carbon, without applying carbon credits. For biodiversity, a number of practices and systemic changes could be supported, with some conditions on regional and networked landscapes, as successful biodiversity support often depends on connected corridors of a certain size. TCA can give a basic argument for the usefulness of these policies and payments and a first gross estimate of required tax and support levels.

In general, governments should support only agriculture and food systems that deliver on the United Nations' Sustainable Development Goals, counterbalancing the powerful vested interests that global and national agribusiness corporations and commodity groups represent.

\section{Notes}

1 Mission Organic Value Chain Development for North East Region (MOVCDNER) is a value chain-based organic farming scheme that began in 2015 and was implemented in the northeastern states of India under the Ministry of Development of the North Eastern region. The mission aims to support the creation of producers' organizations, on-farm and off-farm organic inputs production, certification, post-harvest matters, processing, and marketing.

2 Annex 2, Section 12 of the Agreement on Agriculture. www.wto.org/english/res_e/ publications_e/ai17_e/agriculture_ann2_jur.pdf. 
3 European Agricultural Fund for Rural Development.

4 Available at: www.lawsofindia.org/pdf/sikkim/2014/2014Sikkim10.pdf

\section{References}

Böcker, T. and Finger, R. (2016). European pesticide tax schemes in comparison: An analysis of experiences and developments. Sustainability (Switzerland), 8(4), 1-22. doi:10.3390/su8040378.

Burton, R.J.F. and Schwarz, G. (2013). Result-oriented agri-environmental schemes in Europe and their potential for promoting behavioural change. Land Use Policy, 30(1), 628-641. doi:10.1016/j.landusepol.2012.05.002.

Choi, S. (2015). Agriculture in Korea. Naju: Korea Rural Economic Institute.

European Court of Auditors. (2017). Greening: a more complex income support scheme, not yet environmentally effective. EU Court Audit. 287, 1977-2017.

European Union. (2013). REGULATION (EU) No 1306/2013 OF THE EUROPEAN PARLIAMENT AND OF THE COUNCIL of 17 December 2013 on the financing, management and monitoring of the common agricultural policy. Official Journal of the European Union, 1305, 549-607.

Eyhorn, F., Müller, A., Reganold, J.P., Frison, E., Herren, H.R., Luttikholt, L., Mueller, A., Sanders, J., Scialabba, N.E., Seufert, V., \& Smith, P. (2019). Sustainability in global agriculture driven by organic farming. Nature Sustainability, 2, 253-255. doi:10.1038/s41893-019-0266-6.

Geiger, F., Bengtsson, J., Berendse, F., Weisser, W.W., Emmerson, M., Morales, M.B., Ceryngier, P., Liira, J., Tscharntke, T., Winqvist, C., Eggers, S., Bommarco, R., Pärt, T., Bretagnolle, V., Plantegenest, M., Clement, L.W., Dennis, C., Palmer, C., Oñate, J. J., ... Inchausti, P. (2010). Persistent negative effects of pesticides on biodiversity and biological control potential on European farmland. Basic and Applied Ecology, 11(2), 97-105. doi:10.1016/j.baae.2009.12.001.

Gibbs, K.E., MacKey, R.L., \& Currie, D.J. (2009). Human land use, agriculture, pesticides and losses of imperiled species. Diversity and Distributions, 15(2), 242-253. doi:10.1111/j.1472-4642.2008.00543.x.

IFOAM EU. (2018). Taxation as a tool towards true cost accounting. Available at: www. organicseurope.bio/content/uploads/2020/06/ifoameu_final_study_on_taxation_as_a_ tool_towards_true_cost_accounting.pdf?dd.

IFOAM-Organics International. (2017). The Full Diversity of Organic Agriculture: What We Call Organic. Available at: www.ifoam.bio/sites/default/files/2020-03/position_ full_diversity_of_oa.pdf.

IFOAM-Organics International. (2019). Full Cost Accounting to Transform Agriculture and Food Systems. Available at: www.organicseurope.bio/content/uploads/2020/06/Fullcost-accounting.pdf.

Meehan, T.D., Werling, B.P., Landis, D.A., \& Gratton, C. (2011). Agricultural landscape simplification and insecticide use in the Midwestern United States. Proceedings of the National Academy of Sciences of the United States of America, 108(28), 11500-11505. doi:10.1073/pnas.1100751108.

Meemken, E.M., \& Qaim, M. (2018). Organic Agriculture, Food Security, and the Environment. Annual Review of Resource Economics, 10(1), 39-63. doi:10.1146/ annurev-resource-100517-023252.

Ministry of Environment and Food. (2017). Danish National Actionplan on Pesticides 2017-2021. 
Pacini, G.C., Merante, P., Lazzerini, G., \& Van Passel, S. (2015). Increasing the costeffectiveness of EU agri-environment policy measures through evaluation of farm and field-level environmental and economic performance. Agricultural Systems, 136, 70-78. doi:10.1016/j.agsy.2015.02.004.

Pedersen, A.B. \& Nielsen, H.Ø. (2017). Effectiveness of Pesticide Policies. Environmental Pest Management, December, 297-324. doi:10.1002/9781119255574.ch13.

Pedersen, A.B., Nielsen, H.Ø., \& Daugbjerg, C. (2020). Environmental policy mixes and target group heterogeneity: analysing Danish farmers' responses to the pesticide taxes. Journal of Environmental Policy and Planning, 22(5), 608-619. doi:10.1080/ $1523908 X .2020 .1806047$.

Ponisio, L.C., M'Gonigle, L.K., Mace, K.C., Palomino, J., de Valpine, P., \& Kremen, C. (2015). Diversification practices reduce organic to conventional yield gap. Proceedings of the Royal Society, B, 282. 20141396. doi:10.1098/rspb.2014.1396.

Schader, C., Stolze, M., \& Gattinger, A. (2012). Environmental performance of organic farming. In: Boye, J. I., Arcand, Y. (Eds.), Green Technologies in Food Production and Processing. Food Engineering Series, 183-210. https://doi.org/10. 1007/978-1-4614-1587-9.

Seufert, V. (2018). Comparing yields: Organic versus conventional agriculture. In P. Ferranti, E.M. Berry, \& J.R. Anderson (Eds.). Encyclopedia of Food Security and Sustainability: Volume 3: Sustainable Food Systems and Agriculture, 3, 196-208. doi:10.1016/B978-0-08-100596-5.22027-1.

Seufert, V. \& Ramankutty, N. (2017). Many shades of gray-the context-dependent performance of organic agriculture. Science Advances, 3(3). https://doi.org/10.1126/ sciadv.1602638.

Slunge, D. \& Alpizar, F. (2019). Market-based instruments for managing hazardous chemicals: A review of the literature and future research agenda. Sustainability (Switzerland), 11(16). doi:10.3390/su11164344.

Stolze, M., Sanders, J., Kasperczyk, N., Madsen, G., \& Meredith, S. (2016). CAP 2014 2020: Organic farming and the prospects for stimulating public goods. Brussels: IFOAM EU.

Swiss Federal Office for Agriculture. (2004). Swiss Agricultural Policy. Federal Department of Economic Affairs.

van der Werf, H.M.G., Knudsen, M.T. \& Cederberg, C. (2020). Towards better representation of organic agriculture in life cycle assessment. Nature Sustainability. doi:10.1038/ s41893-020-0489-6.

Willer H., Schlatter B., Trávníček, J., Kemper, L., \& Lernoud, J. (2020). The World of Organic Agriculture - Statistics and Emerging Trends 2020. Research Institute of Organic Agriculture (FiBL), Frick, and IFOAM - Organics International. doi:10.4324/ 9781849775991. 